\title{
Blood pressure-independent effect of candesartan on cardio-ankle vascular index in hypertensive patients with metabolic syndrome
}

This article was published in the following Dove Press journal:

Vascular Health and Risk Management

2 July 2010

Number of times this article has been viewed

\author{
Kanako Bokuda' \\ Atsuhiro Ichihara ${ }^{1,2}$ \\ Mariyo Sakoda' \\ Asako Mito' \\ Kenichiro Kinouchi ${ }^{1}$ \\ Hiroshi Itoh' \\ 'Department of Internal Medicine, \\ Keio University School of Medicine, \\ Tokyo, Japan; ${ }^{2}$ Department of \\ Endocrinology and Anti-Aging \\ Medicine, Keio University School \\ of Medicine, Tokyo, Japan
}

\begin{abstract}
Angiotensin receptor blockers (ARBs) are known to reduce the cardiovascular risk in hypertensive patients. This study was designed to examine the effect of an ARB candesartan on subclinical atherosclerosis assessed by cardio-ankle vascular index (CAVI) in comparison with calcium channel blockers (CCBs) alone in hypertensive patients with metabolic syndrome (MetS). A total of 53 consecutive hypertensive patients with MetS were randomly assigned to the candesartan group, in which candesartan was added on, or the CCBs group, in which CCBs were added on. Clinical and biological parameters were obtained before and after the 12-month treatment period. The primary measure of efficacy was the \%change in CAVI. When treated with candesartan, but not CCBs, CAVI significantly decreased from 8.7 to 7.7 by $11 \%$. Blood pressure (BP) significantly decreased with both treatments, but the differences between groups were not significant. The changes in other parameters remained unchanged in both the groups. Analysis of covariance found that both the BP reduction and the therapy difference contributed to the decrease in CAVI, but the BP reduction was not involved in the decrease in CAVI caused by the difference in the therapy. Candesartan may be a better antihypertensive drug than CCBs to improve subclinical atherosclerosis of patients with MetS.
\end{abstract}

Keywords: albuminuria, ambulatory blood pressure, calcium channel blockers, carotid intima-media thickness

\section{Introduction}

The metabolic syndrome (MetS) describes the presence of a cluster of cardiovascular risk factors including visceral obesity, dyslipidemia, hypertension, and glucose intolerance, resulting in a prothrombotic and proinflammatory states. ${ }^{1,2}$ The presence of the MetS predicts a 2- to 4-fold increase in the risk of cardiovascular disease (CVD) and death. ${ }^{3,4}$ Because of its poor prognosis, treatment strategy for subclinical atherosclerosis, which subsequently results in clinical events of CVD, is attracting worldwide attention. In Japan, according to the criteria established by the Japanese Society of Internal Medicine, a survey by the ministry of health, labor, and welfare, the prevalence of the MetS among males over 40 years of age is $21 \%$, and similar prevalence rate was observed in the United States. ${ }^{5}$

Treatment goal for the MetS is to stop the progression of systemical atherosclerosis. Angiotensin receptor blocker (ARB), irbesartan, is reported to reduce cardiovascular risk factors in patients with MetS. ${ }^{6}$ Candesartan had more beneficial effect in reducing CVD than losartan in obese patients. Compared with the losartan group, the candesartan group had a lower adjusted hazard ratio for total
Correspondence: Atsuhiro Ichihara Keio University School of Medicine, 35 Shinanomachi, Shinjuku-ku,

Tokyo 160-8582, Japan

$\mathrm{Tel}+8 \mathrm{I}-3-5363-3796$

Fax $+81-3-3359-2745$

Email atzichi@sc.itc.keio.ac.jp 
CVD and peripheral artery disease in hypertensive patients with baseline body mass index (BMI) averaging 30.2. ${ }^{7}$ In addition, the subanalysis of Candesartan Antihypertensive Survival Evaluation in Japan (CASE-J) study, which compared the effects of candesartan and amlodipine, showed that candesartan reduced total mortality, particularly in patients with BMI over $27.5 \mathrm{~kg} / \mathrm{m}^{2}$. These might suggest that candesartan's beneficial effect on CVD is prominent in obese patients. However, there has been no study that directly examined the effects of candesartan on the subclinical atherosclerosis or risk of atherosclerotic events in patients with MetS.

The aim of this study was to examine the effects of candesartan on arterial stiffness assessed by cardio-ankle vascular index (CAVI) and augmentation index (AI) in comparison with calcium channel blockers (CCBs) alone in hypertensive patients with MetS. CAVI is reported to be associated with the number of the CVD risk factor independently of blood pressure (BP) in patients with MetS. Recent studies showed that CAVI is less BP-dependent marker for arterial stiffness and detects arterial stiffness due to fibrosis with higher sensitivity and specificity than pulse wave velocity (PWV). ${ }^{8}$ In addition, maximum intima-media thickness (max IMT) of the carotid artery was evaluated as the parameter of subclinical atherosclerosis, and urinary albumin excretion (UAE) was evaluated as a surrogate marker for cardiovascular morbidity and mortality. ${ }^{9}$

\section{Methods}

\section{Study population and design}

Subjects of this study were 53 consecutive hypertensive patients who were previously untreated or treated with CCBs (amlodipine, azelnidipine, benidipine, cilnidipine, efonidipine, nifedipine, and nisoldipine) in the outpatient hypertension clinic of Keio University Medical School Hospital. Patients who were treated with angiotensinconverting enzyme (ACE) inhibitors or ARBs were excluded. All patients fulfilled the diagnostic criteria for MetS established by the Japanese Society of Internal Medicine. Major criteria: waist size $>85 \mathrm{~cm}$ for male and $>90 \mathrm{~cm}$ for female; minor criteria: dyslipidemia (triglycerides [TG] $>150 \mathrm{mg} / \mathrm{dL}$ and/or high-density lipoprotein cholesterol [HDL-C] $<40 \mathrm{mg} / \mathrm{dL}$ ), hypertension (systolic $\mathrm{BP}>130 \mathrm{mmHg}$ and/or diastolic $\mathrm{BP}>85 \mathrm{mmHg}$ ), impaired glucose tolerance (fasting blood glucose $>110 \mathrm{mg} / \mathrm{dL}$ ); presence of major criteria with 2 or more minor criterion. Patients with a history of diabetes for more than 10 years and patients aged 80 years or over were excluded. All hypertensive patients were randomly assigned to the candesartan group or the CCBs group. In the candesartan group, candesartan was added on and the previous treatment was continued. In the CCBs group, kind of CCB was unchanged if previously prescribed and amlodipine was added if untreated. Candesartan was initially prescribed at a dose of $4 \mathrm{mg} / \mathrm{d}$, and dose was subsequently increased to a maximum dose of $16 \mathrm{mg} / \mathrm{d}$ if the target 24-hour ambulatory BP of $<130 / 85 \mathrm{mmHg}$ was not achieved. In the CCBs group, doses were subsequently increased if the target 24-hour ambulatory BP of $<130 / 85 \mathrm{mmHg}$ was not achieved. 24-hour ambulatory BP was monitored every 3 months to assess if the patients achieved BP. In the protocol, if the target BP was not achieved only by dosing up candesartan or CCBs in each group, diuretics or $\beta$-blockers or both were planned to be added on; however, in this study, all patients achieved target 24-hour ambulatory BP without adding diuretics or $\beta$-blockers. Clinical and biological parameters were obtained before and after the 12-month treatment period. This study was approved by the review board of Keio University Medical School Hospital, and informed consent was obtained from every subject. The primary measure of efficacy in this study was the \%change in CAVI, AI, UAE, and carotid IMT.

Brain natriuretic peptide (BNP), potassium $(\mathrm{K})$, creatinine $(\mathrm{Cr})$, uric acid (UA), low-density lipoprotein cholesterol (LDL-C), HDL-C, TG, and glycated albumin (GA) were measured in venous blood samples drawn in the morning after an overnight fast on the same day as the CAVI and AI measurements.

\section{Ambulatory BP monitoring}

The 24-hour ambulatory BP monitoring was performed with an oscillometric-based device (TM-2431; A\&D Corporation, Tokyo, Japan) as described previously. ${ }^{1}$ Briefly, BP was measured every 30 minutes during the day (between 6:00 AM and 10:00 PM) and every 60 minutes during the night (between 10:00 PM and 6:00 AM). Mean values and standard deviations (SDs) of ambulatory BP for each subject were calculated for 24 hours. The SD of the ambulatory BP values was recorded as the variability of ambulatory BP in this study. The nocturnal decrease in BP was calculated as the average systolic BP during the day minus the average systolic BP during the night. The morning BP surge was calculated as the highest systolic BP during the first 2 hours after awaking minus the lowest systolic BP during the night. 


\section{CAVI and $\mathrm{Al}$}

CAVI was measured using a VaSera VS-1000 (Fukuda Denshi, Tokyo, Japan) as described previously. ${ }^{8}$ Briefly, cuffs were applied to the 4 extremities, and electrocardiographic electrodes were attached to the upper extremities. A microphone was placed at the sternal angle to obtain a phonocardiogram. Patients rested in the supine position for at least 10 minutes before the start of monitoring.

AI was measured using an automated tonometric device (HEM-9000AI; Omron Healthcare, Kyoto, Japan) as described previously. ${ }^{8}$ Briefly, peripheral pressure waveforms were recorded over 30 seconds from the radial artery at the wrist with the subjects in a sitting position after at least 5 minutes rest.

\section{Carotid IMT}

Ultrasonography B-mode imaging of the carotid artery was performed with a PowerVision 6000 machine (Toshiba, Tokyo, Japan) at a transducer frequency of 7.5 MHz. Each subject was examined in the supine position. Up to $4 \mathrm{~cm}$ of the common carotid artery and the carotid bulb were scanned bilaterally in the longitudinal and the transverse projections. The images were focused on the far wall of the artery. IMT was defined as the distance between the leading edge of the lumen-intima interface and the far wall, and the greatest IMT value in the bilateral longitudinal projections was recorded as the max IMT. All measurements were performed under blind conditions. The mean intraobserver and interobserver coefficients of variation for max IMT were $4.3 \%$ and $4.7 \%$, respectively.

\section{UAE}

UAE was evaluated on the basis of the albumin-to-Cr ratio in overnight urine samples. Urinary albumin and $\mathrm{Cr}$ concentrations were determined by turbidimetric immunoassay with a Superior-Microalbumin kit (DPC Corporation, Tokyo, Japan) and by the Jaffé reaction with an autoanalyzer.

\section{Statistical analyses}

All statistical analyses were performed with StatView 5.0. software (SAS Institute Inc, Cary, NC, USA). Student $t$ test was used to analyze patients' baseline characteristics, except sex, presence of diabetes, prescription of diuretics and statins, which were analyzed by the $\chi^{2}$ test for independence. The changes in biological parameters were analyzed by the 2-way analysis of variance for repeated measures combined with the Dunnett and Tukey-Kramer post hoc tests. The contribution of changes in BP to \%change in CAVI was tested by analysis of covariance. A $P<0.05$ was considered significant. Data are reported as means $\pm \mathrm{SD}$.

\section{Results \\ Patient characteristics}

Table 1 shows mean age, gender distribution, complication of diabetes, number of patients taking diuretics and statins, waist circumference, CAVI, plasma BNP, UAE, max IMT of the carotid arteries, AI, estimated glomerular filtration rate (eGFR), serum K, Cr, UA, LDL-C, HDL-C, TG, and GA of the candesartan group and the $\mathrm{CCBs}$ group at baseline. Overall mean values of waist circumference and BP of the subjects were $91 \pm 8 \mathrm{~cm}$ and $152 \pm 22 / 95 \pm 12 \mathrm{mmHg}$, respectively. There were no significant differences in baseline variables between

Table I Patient characteristics at baseline

\begin{tabular}{|c|c|c|c|}
\hline & Candesartan & CCBs & $P$ value \\
\hline $\mathrm{N}$ & 27 & 26 & \\
\hline Age, y & $52 \pm 13$ & $56 \pm 8$ & 0.1580 \\
\hline Male, $\mathrm{n}$ & 23 & 16 & 0.0509 \\
\hline Diabetes, $\mathrm{n}$ & 6 & 3 & 0.2987 \\
\hline $\begin{array}{l}\text { Prescription of diuretics, } \\
n\end{array}$ & 4 & 1 & 0.2075 \\
\hline $\begin{array}{l}\text { Prescription of statins, } \\
\mathrm{n}\end{array}$ & 3 & 5 & 0.2660 \\
\hline Waist, $\mathrm{cm}$ & $91.3 \pm 7.9$ & $90.9 \pm 7.9$ & 0.8945 \\
\hline CAVI & $8.7 \pm 1.1$ & $9.1 \pm 0.7$ & 0.4175 \\
\hline Plasma BNP, mg/dL & $18.0 \pm 16.2$ & $13.5 \pm 12.2$ & 0.6294 \\
\hline UAE, log, (mg/gCr) & $1.14 \pm 0.32$ & $1.53 \pm 0.35$ & 0.2007 \\
\hline Max IMT, mm & $0.90 \pm 0.32$ & $1.20 \pm 0.00$ & 0.1322 \\
\hline $\mathrm{Al}, \%$ & $80.1 \pm 12.2$ & $80.8 \pm 14.2$ & 0.9001 \\
\hline eGFR, $\mathrm{mL} / \mathrm{min} / 1.73 \mathrm{~m}$ & $68.4 \pm 21.7$ & $67.5 \pm 18.4$ & 0.8947 \\
\hline $\begin{array}{l}\text { Serum potassium, } \\
\mathrm{mEq} / \mathrm{L}\end{array}$ & $4.2 \pm 0.4$ & $4.1 \pm 0.3$ & 0.5683 \\
\hline $\begin{array}{l}\text { Serum creatinine, } \\
\mathrm{mg} / \mathrm{dL}\end{array}$ & $1.0 \pm 0.6$ & $0.8 \pm 0.3$ & 0.3643 \\
\hline $\begin{array}{l}\text { Serum uric acid, } \\
\mathrm{mg} / \mathrm{dL}\end{array}$ & $6.3 \pm 1.2$ & $5.6 \pm 1.3$ & 0.1405 \\
\hline $\begin{array}{l}\text { Serum LDL-C, } \\
\mathrm{mg} / \mathrm{dL}\end{array}$ & $117 \pm 33$ & $135 \pm 39$ & 0.1914 \\
\hline $\begin{array}{l}\text { Serum HDL-C, } \\
\mathrm{mg} / \mathrm{dL}\end{array}$ & $48 \pm 14$ & $55 \pm 16$ & 0.3206 \\
\hline $\begin{array}{l}\text { Serum triglycerides, } \\
\mathrm{mg} / \mathrm{dL}\end{array}$ & $194 \pm 168$ & $130 \pm 64$ & 0.0811 \\
\hline $\begin{array}{l}\text { Serum glycated albumin, } \\
\mathrm{g} / \mathrm{dL}\end{array}$ & $14.5 \pm 1.8$ & $13.2 \pm 1.1$ & 0.2575 \\
\hline $\begin{array}{l}\text { Plasma active renin } \\
\text { concentration, } \mathrm{pg} / \mathrm{mL}\end{array}$ & $8.5 \pm 6.8$ & $11.8 \pm 15.3$ & 0.4177 \\
\hline
\end{tabular}

Note: Data are mean \pm SD.

Abbreviations: CCBs, calcium channel blockers; CAVI, cardio-ankle vascular index; BNP, brain natriuretic peptide; UAE, urine albumin excretion; Max IMT, maximum intima-media thickness of the carotid arteries; Al, augmentation index; eGFR, estimated glomerular filtration rate; HDL-C, high-density lipoprotein cholesterol; LDL-C, low-density lipoprotein cholesterol; SD, standard deviation. 
the 2 groups. The average dose of candesartan prescribed at the end of the observation period was $13.8 \pm 4.7 \mathrm{mg} / \mathrm{d}$.

\section{Clinic and ambulatory BP}

Table 2 shows the clinic BP and 24-hour ambulatory BP in the candesartan group and the CCBs group at baseline and after 12-month observation period. The baseline values of the clinic systolic/diastolic BP and 24-hour ambulatory systolic/ diastolic BP were similar in the candesartan group and in the CCBs group. The clinic systolic/diastolic BP and 24-hour ambulatory diastolic BP significantly decreased in both the groups. However, 24-hour ambulatory systolic BP and BP variability assessed on the basis of the SD of 24-hour systolic BP remained unchanged in both the groups. The nocturnal BP decrease and morning BP surge were similar in both the groups, and they had not changed significantly during the 12-month treatment period in either group.

\section{Target-organ damage}

Figure 1A shows that CAVI decreased significantly, from $8.7 \% \pm 1.1 \%$ to $7.7 \% \pm 0.8 \%$ by $-11 \% \pm 10 \%$, in the candesartan group, but remained unchanged in the CCBs group $(9.1 \% \pm 0.7 \%$ to $8.9 \% \pm 0.9 \%$ by $2 \% \pm 8 \%)$. Figure $1 \mathrm{~B}$ shows \%change in CAVI during the 12-month treatment period with candesartan or $\mathrm{CCBs}$, and the values differed significantly among the 2 groups. Figure 2 shows plasma BNP, UAE, max IMT, and AI values at baseline and 12 months after the treatment with candesartan or CCBs. They remained unchanged during the 12-month treatment period and were similar in both the groups.

\section{Factors affecting CAVI}

In the candesartan group, CAVI and BP (clinic systolic/ diastolic and 24-hour ambulatory diastolic) values significantly decreased during the 12-month treatment period. Table 3 shows that the decreases in both 24-hour ambulatory systolic/diastolic BP significantly contributed to the \%decrease in CAVI during the treatment period. However, no interactive effect between the treatments and the decreases in 24-hour ambulatory BP was observed, suggesting that the decrease in 24-hour ambulatory BP caused by candesartan did not contribute to the decrease in CAVI of the hypertensive patients. The changes in clinic systolic/ diastolic BP, variability of 24-hour BP, nocturnal decrease or morning surge values did not contribute to the decrease in CAVI during the 12-month treatment period.

\section{Parameters of renal function and metabolism}

Figure 3 shows eGFR, serum $\mathrm{K}, \mathrm{Cr}$, and UA values at baseline and 12 months after the treatment with candesartan or CCBs. They remained unchanged during the 12-month treatment period and were similar in both the groups.

Figure 4 shows LDL-C, HDL-C, TG, and GA values at baseline and 12 months after the treatment with candesartan and CCBs. They remained unchanged during the 12-month treatment period and were similar in both the groups.

\section{Discussion}

When treated with candesartan, CAVI significantly decreased in patients with MetS. At the same time, 24-hour ambulatory BP significantly decreased, both in the candesartan group and in the CCBs group. In the candesartan group, systolic and diastolic BPs decreased by $36 \mathrm{mmHg}$ and $24 \mathrm{mmHg}$, respectively, and in the CCBs group, systolic and diastolic BPs decreased by $11 \mathrm{mmHg}$ and $9 \mathrm{mmHg}$, respectively. Although BP seemed to decrease more in the candesartan group, there was no statistical significant difference between both the groups. The decrease

Table 2 Clinic and ambulatory BP before and after treatments

\begin{tabular}{|c|c|c|c|c|c|}
\hline & \multicolumn{2}{|c|}{ Candesartan $(n=26)$} & \multicolumn{2}{|c|}{ CCBs $(n=27)$} & \multirow{2}{*}{$\begin{array}{l}\text { Intergroup } \\
P \text { value }\end{array}$} \\
\hline & Baseline & $12 \mathrm{mo}$ & Baseline & $12 \mathrm{mo}$ & \\
\hline \multicolumn{6}{|l|}{ Clinic } \\
\hline Systolic BP & $157 \pm 23$ & $136 \pm 13^{*}$ & $156 \pm 21$ & $143 \pm 9^{*}$ & 0.7033 \\
\hline Diastolic BP & $99 \pm 12$ & $87 \pm 9^{*}$ & $95 \pm 11$ & $87 \pm 8^{*}$ & 0.5969 \\
\hline \multicolumn{6}{|l|}{ 24-h ambulatory BP } \\
\hline Systolic BP & $143 \pm 15$ & $120 \pm 15$ & $140 \pm 1 \mid$ & $124 \pm 12$ & 0.3509 \\
\hline Diastolic BP & $92 \pm 10$ & $76 \pm 7^{*}$ & $88 \pm 5$ & $77 \pm 4^{*}$ & 0.2478 \\
\hline Variability & $20 \pm 11$ & $16 \pm 3$ & $20 \pm 5$ & $19 \pm 5$ & 0.7718 \\
\hline Nocturnal decrease & $16 \pm 7$ & $10 \pm 13$ & $17 \pm 11$ & $18 \pm 13$ & 0.5592 \\
\hline Morning surge & $47 \pm 23$ & $32 \pm 11$ & $46 \pm 16$ & $33 \pm 17$ & 1.0000 \\
\hline
\end{tabular}

Note: Data are mean \pm SD. ${ }^{*} P<0.05$ vs baseline.

Abbreviations: BP, blood pressure; $\mathrm{CCBs}$, calcium channel blockers; SD, standard deviation. 
A

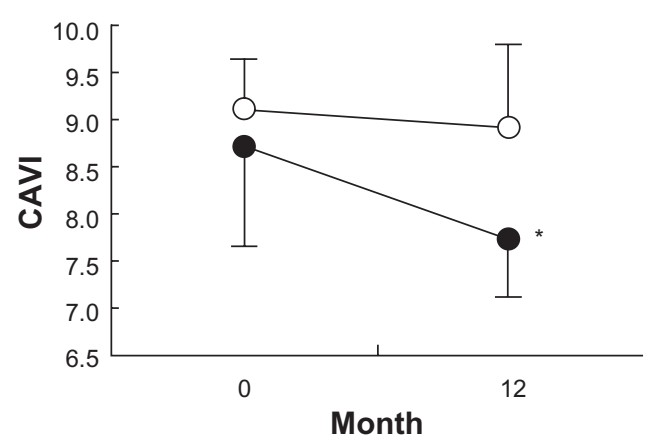

B

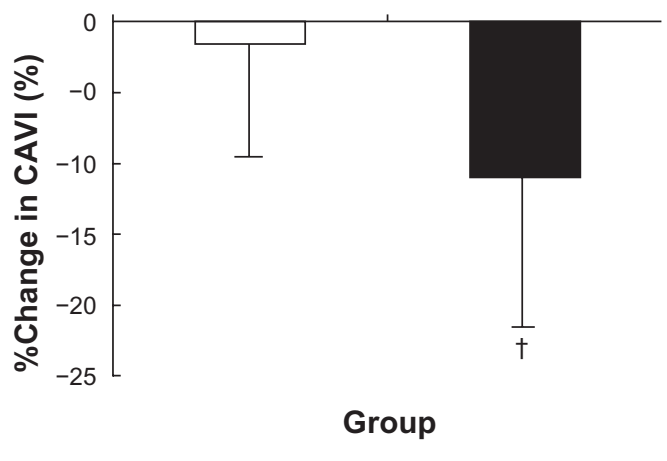

Figure I Cardio-ankle vascular index (CAVI) A) and \%change in CAVI B) during I2-month treatment with candesartan (closed circles and bars, $\mathrm{n}=27)$ and calcium channel blockers (open circles and bars, $\mathrm{n}=26$ ).

Notes: ${ }^{*} P<0.05$ vs 0 month. ${ }^{\dagger} P<0.05$ vs calcium channel blockers.

in 24-hour ambulatory BP contributed to the \%decrease in CAVI. Analysis of covariance was performed to examine if the decrease in 24-hour ambulatory BP is the only factor contributed to the \%decrease in CAVI in the candesartan group. As a result, the difference in the treatment also contributed to the \%decrease in CAVI, and no interactive effect of the decrease in 24-hour ambulatory BP on the decrease in CAVI due to the difference in the treatment was observed. This suggests that candesartan may decrease CAVI at least in part through its BP-independent effects, although the decrease in $\mathrm{BP}$ was one of the contributors to the decrease in CAVI. The suppression of the renin-angiotensin system by candesartan and/or its own pharmacological effects may contribute to the decrease in CAVI. Angiotensin II accelerates the development of atherosclerosis by activating angiotensin II type 1 receptors (AT1Rs) that then promote superoxide anion generation and oxidative stress, leading to activation of nuclear transcription factor and endothelial dysfunction. ${ }^{10}$ Mechanical stretching has been cited as the cause of cardiac hypertrophy, and investigation into this process with ARBs has indicated that AT1Rs are involved in stretch-induced hypertrophic responses. Mechanical stretching stimulates
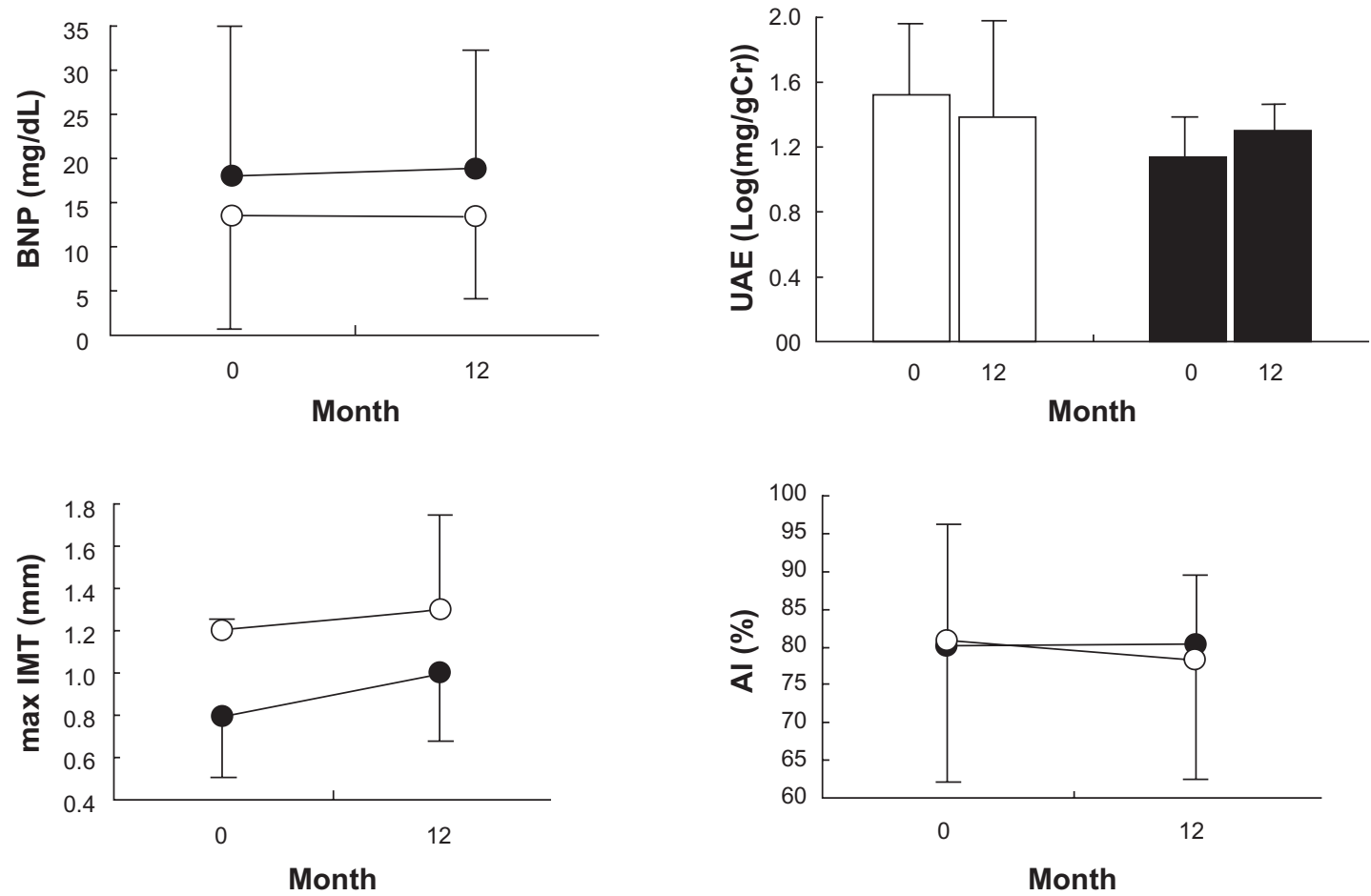

Figure 2 Plasma levels of brain natriuretic peptide (BNP), urinary albumin excretion (UAE), maximum intima-media thickness of the carotid arteries (max IMT), and Al at baseline and after 12 months of treatment with candesartan (closed circles and bars, $n=27$ ) and calcium channel blockers (open circles and bars, $n=26$ ). 
Table 3 Effects of candesartan and \%change in BP on \%change in CAVI

\begin{tabular}{|c|c|c|c|c|}
\hline Analysis of covariance & Coefficient & Standard error & $t$-test & $P$ value \\
\hline \multicolumn{5}{|l|}{ Clinic systolic BP } \\
\hline Group (candesartan vs CCBs) & -2.373 & 2.896 & -0.819 & 0.4246 \\
\hline \%Change in systolic BP & 0.358 & 0.229 & 1.562 & 0.1379 \\
\hline Group $\times \%$ change in systolic BP & 0.116 & 0.229 & 0.507 & 0.6192 \\
\hline \multicolumn{5}{|l|}{ Clinic diastolic BP } \\
\hline Group (candesartan vs CCBs) & -1.120 & 3.528 & -0.317 & 0.7551 \\
\hline \%Change in diastolic BP & 0.148 & 0.346 & 0.427 & 0.6748 \\
\hline Group $\times \%$ change in diastolic BP & 0.332 & 0.346 & 0.959 & 0.3517 \\
\hline \multicolumn{5}{|l|}{ 24-h ambulatory systolic BP } \\
\hline Group (candesartan vs CCBs) & -14.855 & 1.998 & -7.433 & 0.0176 \\
\hline \%Change in systolic BP & -1.237 & 0.141 & -8.751 & 0.0128 \\
\hline Group $\times$ \%change in 24 -h systolic BP & 0.264 & 0.141 & 1.866 & 0.2031 \\
\hline \multicolumn{5}{|l|}{ 24-h ambulatory diastolic BP } \\
\hline Group (candesartan vs CCBs) & -19.870 & 3.728 & -5.330 & 0.0334 \\
\hline \%Change in diastolic BP & -1.825 & 0.245 & -7.453 & 0.0175 \\
\hline Group $\times \%$ change in 24 -h diastolic BP & 0.258 & 0.245 & 1.055 & 0.4019 \\
\hline \multicolumn{5}{|l|}{$\mathrm{BP}$ variability } \\
\hline Group (candesartan vs CCBs) & -7.478 & 2.413 & -3.099 & 0.0903 \\
\hline \%Change in variability of $\mathrm{BP}$ & -0.013 & 0.099 & -0.128 & 0.9100 \\
\hline Group $\times \%$ change in variability of BP & 0.365 & 0.099 & 3.691 & 0.0662 \\
\hline \multicolumn{5}{|l|}{ Nocturnal decrease } \\
\hline Group (candesartan vs CCBs) & -7.048 & 6.557 & -1.075 & 0.3949 \\
\hline \%Change in nocturnal decrease & 0.036 & 0.78 & 0.464 & 0.6885 \\
\hline Group $\times \%$ change in nocturnal decrease & 0.036 & 0.078 & 0.020 & 0.9861 \\
\hline \multicolumn{5}{|l|}{ Morning surge } \\
\hline Group (candesartan vs CCBs) & -8.894 & 4.558 & -1.951 & 0.1903 \\
\hline$\%$ Change in morning surge & -0.083 & 0.088 & -0.948 & 0.4432 \\
\hline Group $\times \%$ change in morning surge & 0.064 & 0.088 & 0.724 & 0.5441 \\
\hline
\end{tabular}

Abbreviations: BP, blood pressure; CAVI, cardio-ankle vascular index; CCBs, calcium channel blockers.

AT1Rs independently of angiotensin II, and candesartan was reported to inhibit this stimuli as an inverse agonist. ${ }^{11}$ This mechanism may also work present in the arterial smooth muscle, and candesartan might have suppressed the hypertrophic change of the arterial walls resulting in the decrease in CAVI. In addition, a previous study demonstrated that a long-term treatment with candesartan increases the expression of peroxisome proliferator-activated receptor- $\gamma$ (PPAR- $\gamma$ ) messenger RNA in rats. ${ }^{12}$ Since stimulation of PPAR $-\gamma$ resulted in the decrease in $\mathrm{PWV}^{13}$ through up-regulating adiponectin and down-regulating inflammatory markers in the plasma, ${ }^{14}$ antiatherosclerotic effects of PPAR $\gamma$ might be also involved in the reduction of CAVI by the candesartan treatment.

Studies showed that the 24-month treatment with candesartan reduced $\mathrm{AI}^{15}$ and decreased carotid IMT by enhancing nitric oxide and decreasing oxidative stress in hypertensive patients, ${ }^{16}$ although 12-month treatment with candesartan was reported not to decrease carotid max IMT. ${ }^{17}$ In this study, AI or carotid max IMT remained unchanged during 12-month treatment with candesartan. More extended treatment period with candesartan might be required to obtain the significant improvement of AI and carotid IMT.

Metabolic parameters, such as serum levels of LDL-C, HDL-C, TG, and GA, remained unchanged in this study, as well as in a recent study which showed that candesartan had no effect on serum lipoprotein levels in hypertensive patients. ${ }^{10}$ In the CASE-J study, however, new-onset diabetes occurred fewer in patients taking candesartan than in those taking amlodipine resulting in a $36 \%$ relative risk reduction, suggesting beneficial effect of candesartan on glucose tolerance. ${ }^{20}$ The patients in the CASE-J study were treated for 3.2 years, whereas patients in this study were treated for only 1 year. To obtain beneficial effect of candesartan on glucose tolerance, longer treatment period may be required.

Among ARBs, candesartan is known to have more beneficial effect in reducing CVD, in patients whose BMI was $30.2 .^{7}$ The subanalysis of CASE-J study, which compared the effects of candesartan and amlodipine, showed that candesartan reduces total mortality, particularly in patients with BMI over $27.5 \mathrm{~kg} / \mathrm{m}^{2}$. 

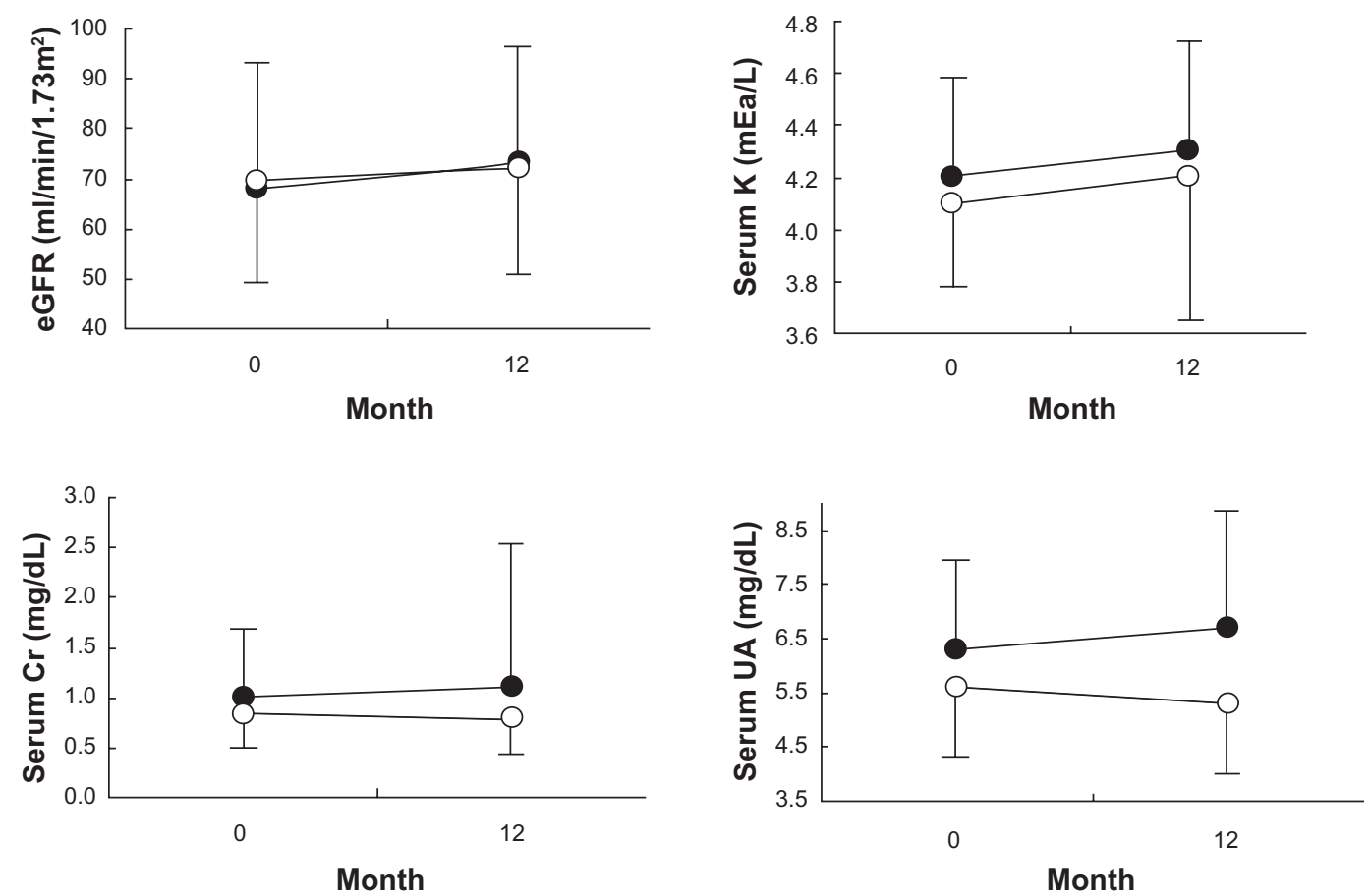

Figure 3 Estimated glomerular filtration rate (eGFR), serum potassium (K), serum creatinine ( $\mathrm{Cr}$ ), and serum uric acid (UA) at baseline and after 12 months of treatment with candesartan (closed circles, $n=27$ ) and calcium channel blockers (open circles, $n=26$ ).

One of the limitations in this study was that hard outcomes were not examined. Also, the trial population was comparatively small in number and the treatment period was comparatively short. Although there were no significant differences in baseline characteristics between both groups, candesartan group tended to be younger, more frequently male and diabetic. Since different types of CCBs were prescribed in the CCBs group, we have to note that this
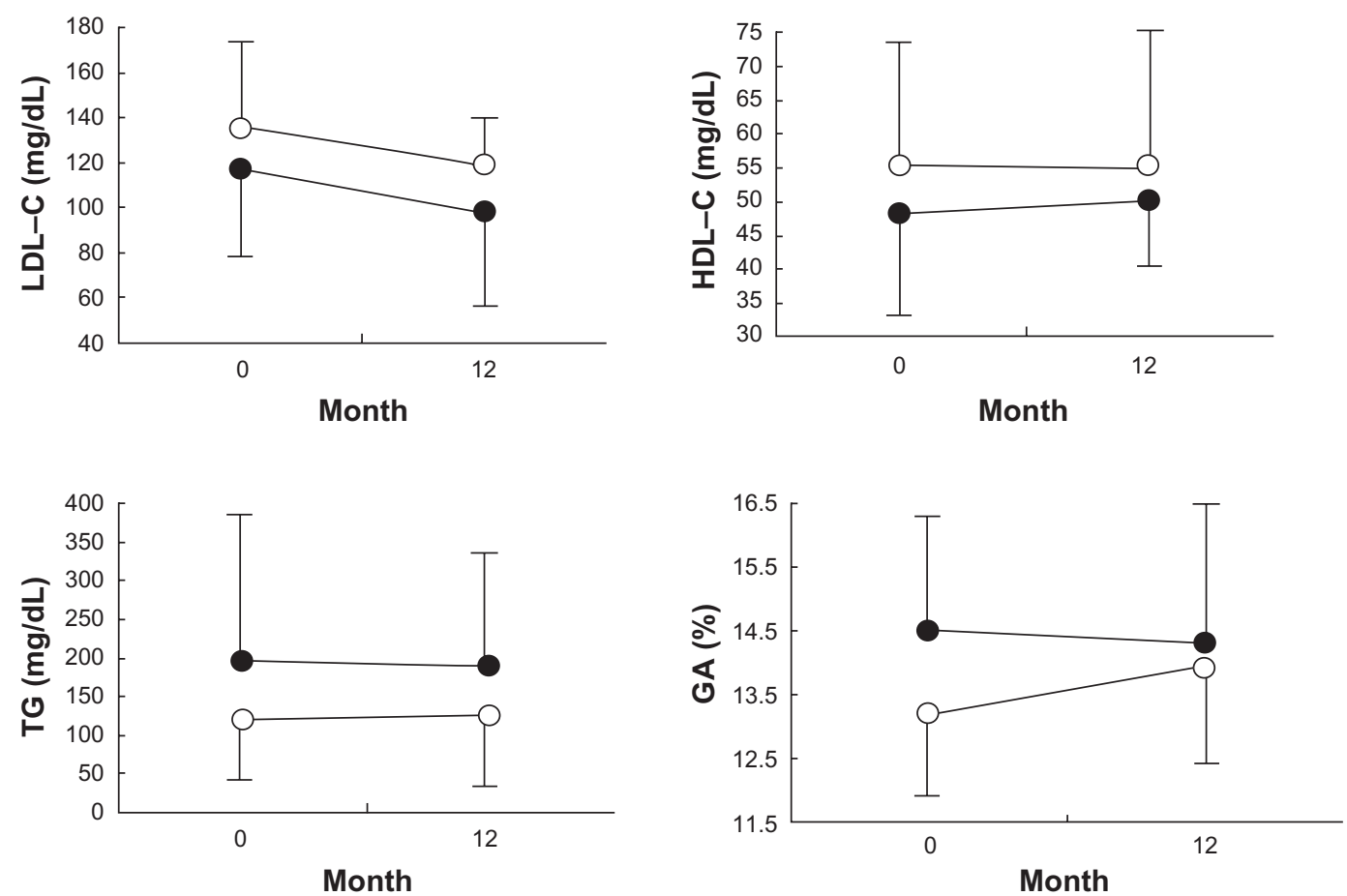

Figure 4 Serum levels of low-density lipoprotein cholesterol (LDL-C), high-density lipoprotein cholesterol (HDL-C), triglycerides (TG), and glycated albumin (GA) at baseline and after 12 months of treatment with candesartan (closed circles, $n=27$ ) and calcium channel blockers (open circles, $n=25$ ). 
study cannot deny the effectiveness of a specific CCB. These are the limitations of this study, and further studies will be needed to confirm the efficacy of candesartan.

In conclusion, candesartan significantly decreased CAVI in hypertensive patients with MetS, but CCBs did not, although both antihypertensive drugs similarly decreased BPs. Candesartan may be an useful antihypertensive drug to improve subclinical atherosclerosis developed in hypertensive patients with MetS.

\section{Acknowledgments}

We appreciate the skillful secretarial work of Ms Chika Miki. This work was supported in part by a grant from Ministry of Education, Science, and Culture of Japan (17390249).

\section{Disclosure}

The authors report no conflicts of interest in this work.

\section{References}

1. Guidelines Subcommittee of the WHO/ISH Mild Hypertension Liaison Committee. 1993 guidelines for the management of mild hypertension. Memorandum from a World Health Organization/International Society of Hypertension meeting. Hypertension. 1993;22:392-403.

2. Third Report of the National Cholesterol Education Program (NCEP) Expert Panel on Detection, Evaluation, and Treatment of High Blood Cholesterol in Adults (Adult Treatment Panel III) final report. Circulation. 2002;106:3143-3421.

3. Isomaa B, Almgren P, Tuomi T, et al. Cardiovascular morbidity and mortality associated with the metabolic syndrome. Diabetes Care. 2001; 24:683-689.

4. Lakka HM, Laaksonen DE, Lakka TA, et al. The metabolic syndrome and total and cardiovascular disease mortality in middle-aged men. JAMA. 2002;288:2709-2716.

5. Ford ES, Giles WH, Dietz WH. Prevalence of the metabolic syndrome among US adults: findings from the third National Health and Nutrition Examination Survey. JAMA. 2002;287:356-359.

6. Kintscher U, Bramlage P, Paar WD, Thoenes M, Unger T. Irbesartan for the treatment of hypertension in patients with the metabolic syndrome: a sub analysis of the Treat to Target post authorization survey. Prospective observational, two armed study in 14,200 patients. Cardiovasc Diabetol. 2007;6:12.
7. Kjeldsen SE, Stalhammar J, Hasvold P, Bodegard J, Olsson U, Russell D. Effects of losartan vs candesartan in reducing cardiovascular events in the primary treatment of hypertension. J Hum Hypertens. 2010;24:263-273.

8. Ichihara A, Yamashita N, Takemitsu T, et al. Cardio-ankle vascular index and ankle pulse wave velocity as a marker of arterial fibrosis in kidney failure treated by hemodialysis. Am J Kidney Dis. 2008; 52:947-955.

9. Pontremoli R, Leoncini G, Viazzi F, et al. Evaluation of subclinical organ damage for risk assessment and treatment in the hypertensive patient: role of microalbuminuria. J Am Soc Nephrol. 2006;17:S112-S114.

10. Koh KK, Quon MJ, Han SH, Chung WJ, Kim JA, Shin EK. Vascular and metabolic effects of candesartan: insights from therapeutic interventions. J Hypertens Suppl. 2006;24:S31-S38.

11. Zou Y, Akazawa H, Qin Y, et al. Mechanical stress activates angiotensin II type 1 receptor without the involvement of angiotensin II. Nat Cell Biol. 2004;6:499-506.

12. Zorad S, Dou JT, Benicky J, et al. Long-term angiotensin II AT1 receptor inhibition produces adipose tissue hypotrophy accompanied by increased expression of adiponectin and PPARgamma. Eur $J$ Pharmacol. 2006;552:112-122.

13. Ryan KE, McCance DR, Powell L, McMahon R, Trimble ER. Fenofibrate and pioglitazone improve endothelial function and reduce arterial stiffness in obese glucose tolerant men. Atherosclerosis. 2007; 194:e123-e130.

14. Samaha FF, Szapary PO, Iqbal N, et al. Effects of rosiglitazone on lipids, adipokines, and inflammatory markers in nondiabetic patients with low high-density lipoprotein cholesterol and metabolic syndrome. Arterioscler Thromb Vasc Biol. 2006;26:624-630.

15. Spratt JC, Webb DJ, Shiels A, Williams B. Effects of candesartan on cardiac and arterial structure and function in hypertensive subjects. J Renin Angiotensin Aldosterone Syst. 2001;2:227-232.

16. Ono H, Minatoguchi S, Watanabe K, et al. Candesartan decreases carotid intima-media thickness by enhancing nitric oxide and decreasing oxidative stress in patients with hypertension. Hypertens Res. 2008;31:271-279.

17. Ichihara A, Kaneshiro Y, Takemitsu T, Sakoda M, Itoh H. Benefits of candesartan on arterial and renal damage of non-diabetic hypertensive patients treated with calcium channel blockers. Am J Nephrol. 2006;26:462-468.

18. Bilous R, Chaturvedi N, Sjolie AK, et al. Effect of candesartan on microalbuminuria and albumin excretion rate in diabetes: three randomized trials. Ann Intern Med. 2009;151:11-20, W3-W4.

19. Ito $\mathrm{S}$. Usefulness of RAS inhibition depends on baseline albuminuria. Nat Rev Nephrol. 2010;6:10-11.

20. Ogihara T, Fujimoto A, Nakao K, Saruta T. ARB candesartan and CCB amlodipine in hypertensive patients: the CASE-J trial. Expert Rev Cardiovasc Ther. 2008;6:1195-1201.
Vascular Health and Risk Management

\section{Publish your work in this journal}

Vascular Health and Risk Management is an international, peerreviewed journal of therapeutics and risk management, focusing on concise rapid reporting of clinical studies on the processes involved in the maintenance of vascular health; the monitoring, prevention and treatment of vascular disease and its sequelae; and the involvement of

\section{Dovepress}

metabolic disorders, particularly diabetes. This journal is indexed on PubMed Central and MedLine. The manuscript management system is completely online and includes a very quick and fair peer-review system, which is all easy to use. Visit http://www.dovepress.com/ testimonials.php to read real quotes from published authors. 